\title{
Relationships between seasonal changes in serum testosterone concentrations, scrotal circumference and sperm morphology of male wapiti (Cervus elaphus)
}

\author{
J. C. Haigh*, W. F. Cates*, G. J. Glover* and N. C. Rawlings $\dagger$ \\ * Department of Herd Medicine and Theriogenology and + Department of Veterinary Physiological \\ Sciences, Western College of Veterinary Medicine, University of Saskatchewan, Saskatoon, \\ Saskatchewan, Canada S7N OWO
}

\begin{abstract}
Summary. One 2-year-old and 4 adult ( $>3$ years old) wapiti were studied throughout 1 year. Serum testosterone concentrations, scrotal circumference and \% normal spermatozoa in the ejaculate peaked around September. Testosterone levels fell sharply by November, but scrotal circumference declined less sharply and normal sperm production occurred until March. There were indications of a secondary peak in these values around February-March.
\end{abstract}

\section{Introduction}

It has been recognized since the time of Aristotle (384-322 B.C.) that deer are seasonal breeders. Many detailed field studies of the reproductive behaviour of wapiti (Cervus elaphus nelsoni) have been made. Struhsaker (1967) described the peak of breeding activity in September and October and Follis (1972), in his study of reproductive potential of yearling males, found that they were fertile, but had a delayed breeding season when compared to mature bulls. There are sporadic reports of wapiti and red deer calvings as late as October, indicating breeding in February, but in the wild these calves may not survive because of maternal agalactia (Guinness, Lincoln \& Short, 1971).

Studies of endocrine profiles and changes in semen quality of red deer (Lincoln, 1971; Krzywinski \& Jaczewski, 1978) have confirmed that, while testosterone concentrations peak for only a brief period, good quality semen (in terms of sperm morphology) can be collected from stags for several months.

\section{Materials and Methods}

Five wapiti bulls, aged 2, 4, 5, 7 and 10 years, were held in pens and fed a constant ration (14\% protein pellet and alfalfa hay ad libitum). These animals were restrained, when possible, every $12-$ 17 days for collection of data; exceptions occurred in October due to a problem with the handling complex, and in late December due to inclement weather. In June and July the animals were chemically immobilized using a mixture of carfentanil (Janssen Pharmaceutica, 2340 Beerse, Belgium) and xylazine hydrochloride (Rompun; Bayvet, Cutter Labs, Mississauga, Ontario). From August all procedures were carried out on animals physically restrained in a chute and squeeze. 
Serum was harvested from blood samples collected from the cephalic vein and stored at $-15^{\circ} \mathrm{C}$ until assayed. Blood samples were taken from immobilized animals within a few minutes of recumbency. Serum was analysed for testosterone using an established radioimmunoassay (Cook, Rawlings \& Kennedy, 1982), but without chromatography. Samples of $200 \mu l$ were extracted in duplicate with diethyl ether and the extracts assayed directly using a specific antiserum. Crossreactions with the antiserum used were: cortisol $<0.02 \%$, oestradiol- $17 \beta 0.2 \%$, progesterone $0.2 \%$ and dihydrotestosterone $100 \%$. All estimates were corrected for procedural losses, extraction efficiency was $86 \pm 8 \cdot 3 \%$ (mean \pm s.d.) $(n=25)$. The sensitivity of the assay, defined as the blank plus twice the standard deviation of the blank, was $34 \mathrm{pg}(n=23)$ per assay tube. Intra-assay coefficient of variation was $15 \%(n=8)$ and inter-assay coefficient of variation was $22 \%(n=27)$; these figures are based on reference sera analysed in every assay $(3.78 \pm 0.96 \mathrm{mg} / \mathrm{ml})$.

Scrotal circumference was measured (always by J. C. H.) at its maximum using a metal tape (Lane Manufacturing, Denver, Colorado, U.S.A.) with the testes held firmly in the distal part of the scrotum (Chenoweth \& Ball, 1980).

Semen was collected by electroejaculation. The probe used was $5.5 \mathrm{~cm}$ in diameter, $29.0 \mathrm{~cm}$ in length, and had three longitudinal electrodes $1.0 \mathrm{~cm}$ apart on the ventral surface. Electrical stimulation was applied by one of two standard ejaculators (Nicholson Transjector, Denver, Colorado, U.S.A. or the Pulsator II, Lane Manufacturing) with a $120-\mathrm{V}, 60-\mathrm{Hz}$ power source. Since these machines do not operate well below room temperature they were encased in a standard motor vehicle battery blanket, and kept inside a warm vehicle when not in use.

The collecting apparatus consisted of a rubber conical device, as used for domestic bulls (Bos taurus), with a calibrated tube attached. To standardize temperature, a 20-litre pail encased in an insulated box was used as a water bath which was maintained at $38^{\circ} \mathrm{C}$, thus allowing satisfactory collections to be made in adverse weather conditions.

The wapiti were prepared for ejaculation using the same technique as for domestic bulls; the rectum was evacuated and the accessory sex glands massaged while being measured. The probe was inserted to its full length. Electrical stimulation was carried out as has been described for the domestic bull (Ball, 1980). On those occasions when wapiti were immobilized, attempts at collection were made with the animal in lateral recumbency; two people worked on the penis and prepuce, one held the probe in place, and a fourth operated the ejaculator.

Sperm smears stained with an aniline blue-eosin stain were used to evaluate morphology and live-dead ratio. Morphological evaluation was based on that used for the domestic bull (Chenoweth $\&$ Ball, 1980). Differences in the percentages of normal spermatozoa with season were compared by one-way analysis of variance. The mean percentage of normal spermatozoa for samples collected from the bulls on a given date were compared by Duncan's multiple range test.

\section{Results}

\section{Testosterone concentrations}

Testosterone concentrations in the 4 adult ( $>3$ years old) wapiti rose sharply in the autumn over a period of 4-8 weeks and declined even more rapidly from the peak levels. In the 2-year-old wapiti small peaks occurred in September, November, February and April, but at no time did this animal exhibit levels of testosterone as high as those measured in adults. Serum testosterone levels of all wapiti fell to about $1 \mathrm{ng} / \mathrm{ml}$ by late November and fluctuated between 0.6 and $2.1 \mathrm{ng} / \mathrm{ml}$ until midMarch. In April they were at their lowest levels (Text-fig. 1a).

\section{Scrotal circumference}

Scrotal circumference changed throughout the year (Text-fig. 1b) and there were significant $(P<0.001)$ differences between individual wapiti and with season. Values for the 7-year-old bull 


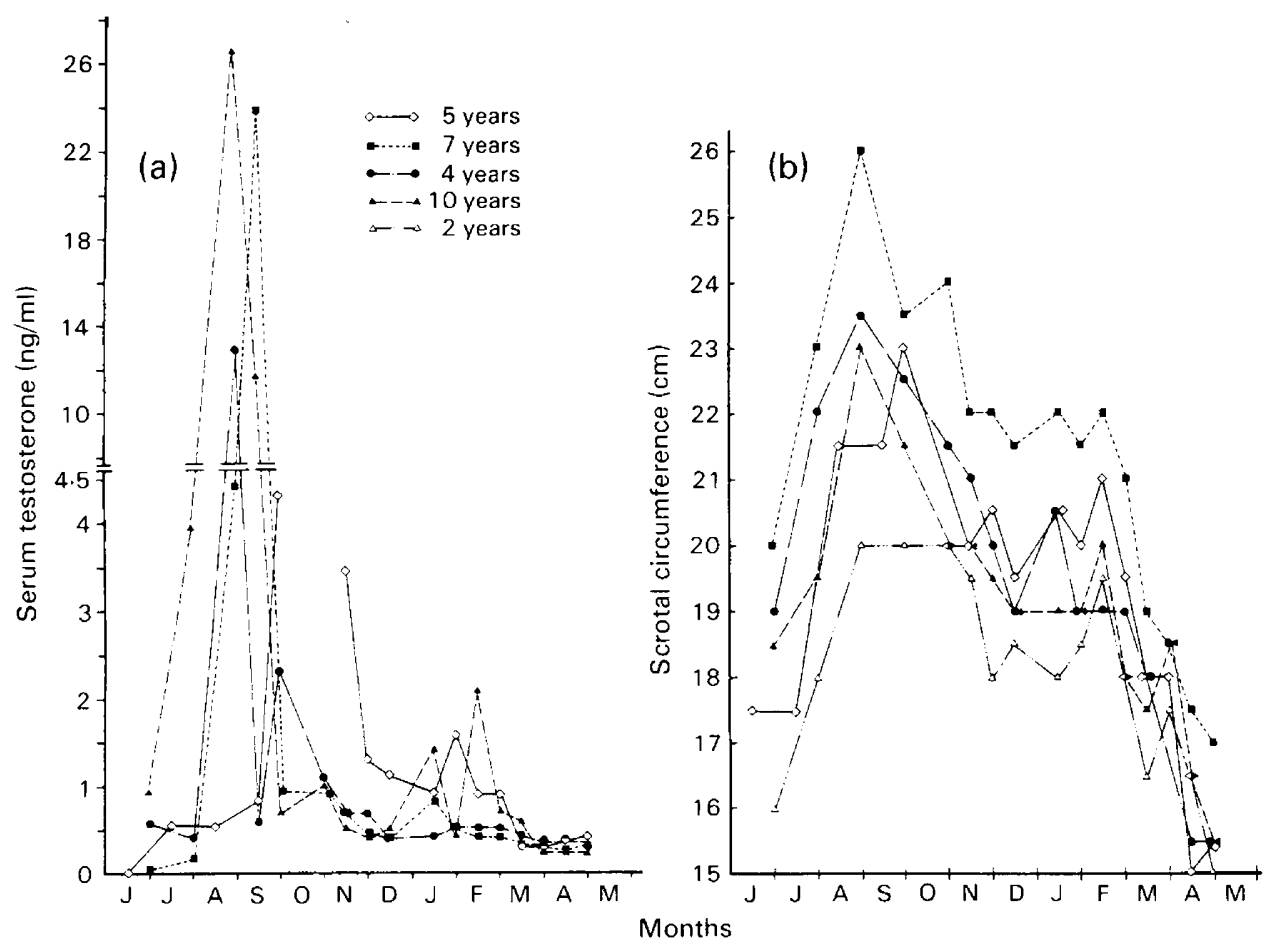

Text-fig. 1. Changes in (a) serum testosterone concentrations and (b) scrotal circumference of wapiti males. Blood samples were collected and measurements were made twice monthly.

were significantly greater and for the 2-year-old were significantly less than those for the other bulls. The values for the other 3 animals were similar to one another.

Scrotal circumference increased sharply over a period of 2 months from early July to peak at the beginning of September, followed by a decline for $2 \frac{1}{2}-3$ months until mid-November or early December. Over the next $2 \frac{1}{2}-3$ months there were fluctuations in individual animals ranging from 0.5 to $1.5 \mathrm{~cm}$ until another sharp decline over $2 \frac{1}{2}$ months occurred to the low point at the end of April.

\section{Semen collection}

Electroejaculation was performed throughout the year at a wide range of ambient temperatures. In immobilized animals it was sometimes difficult to exteriorize the penis. During summer months collections were made early in the morning to avoid the heat of the day. During colder times of the year collections were made when temperatures were estimated to be at a maximum. Maximum temperatures on the days of collection varied from $+32^{\circ} \mathrm{C}$ to $-31^{\circ} \mathrm{C}$. Minimum temperatures on these days ranged from $14^{\circ} \mathrm{C}$ to $-37^{\circ} \mathrm{C}$.

On 15 June and 3 July no spermatozoa were seen in ejaculates. On 13 July, 3 of 4 ejaculates contained small numbers of spermatozoa, mixed with cellular debris. On 30 July all ejaculates contained spermatozoa of variable numbers and with different types of defect. The percentage of normal spermatozoa reached a maximum on 1 September (Text-fig. 2). The percentage of normal spermatozoa in ejaculates between 1 September and 15 March did not differ significantly from one another. On 29 October an electrical failure prevented the collection of more than 2 ejaculates. On 5 January the ambient temperature was $-31^{\circ} \mathrm{C}$ and collection attempts were discontinued after the first 2 animals had been handled. When compared by analysis of variance the results for the 4 adult wapiti showed significant differences on 30 July and 1 April $(P<0.0001)$. At the end of April only one ejaculate contained any spermatozoa. 




Text-fig. 2. Changes in mean ( \pm s.d.) percentage of normal spermatozoa in ejaculates of 4 wapiti $>3$ years old. Numbers in parentheses indicate the number of ejaculates containing spermatozoa if less than 3 .



Text-fig. 3. Seasonal changes in \% normal spermatozoa, scrotal circumference and serum testosterone concentration of 4 captive wapiti $>3$ years old. Data collected twice monthly.

\section{PLATE 1}

Wapiti spermatozoa

Fig. 1. Normal (top) and abnormal spermatozoa (short, broad head and bent midpiece) in ejaculate of 24 September $1981 . \times 1200$.

Fig. 2. 'Diadem' defect in equatorial region of spermatozoa (24 September 1981). $\times 1800$.

Fig. 3. Normal spermatozoa (right) and knobbed acrosome in same ejaculate as in Fig. 2. $\times 1800$.

Fig. 4. Proximal droplets (1 April 1982) $\times 1800$.

Fig. 5. Defective spermatozoa with large cytoplasmic remnants and small heads (15 April 1982). $\times 2300$. 
PLATE I
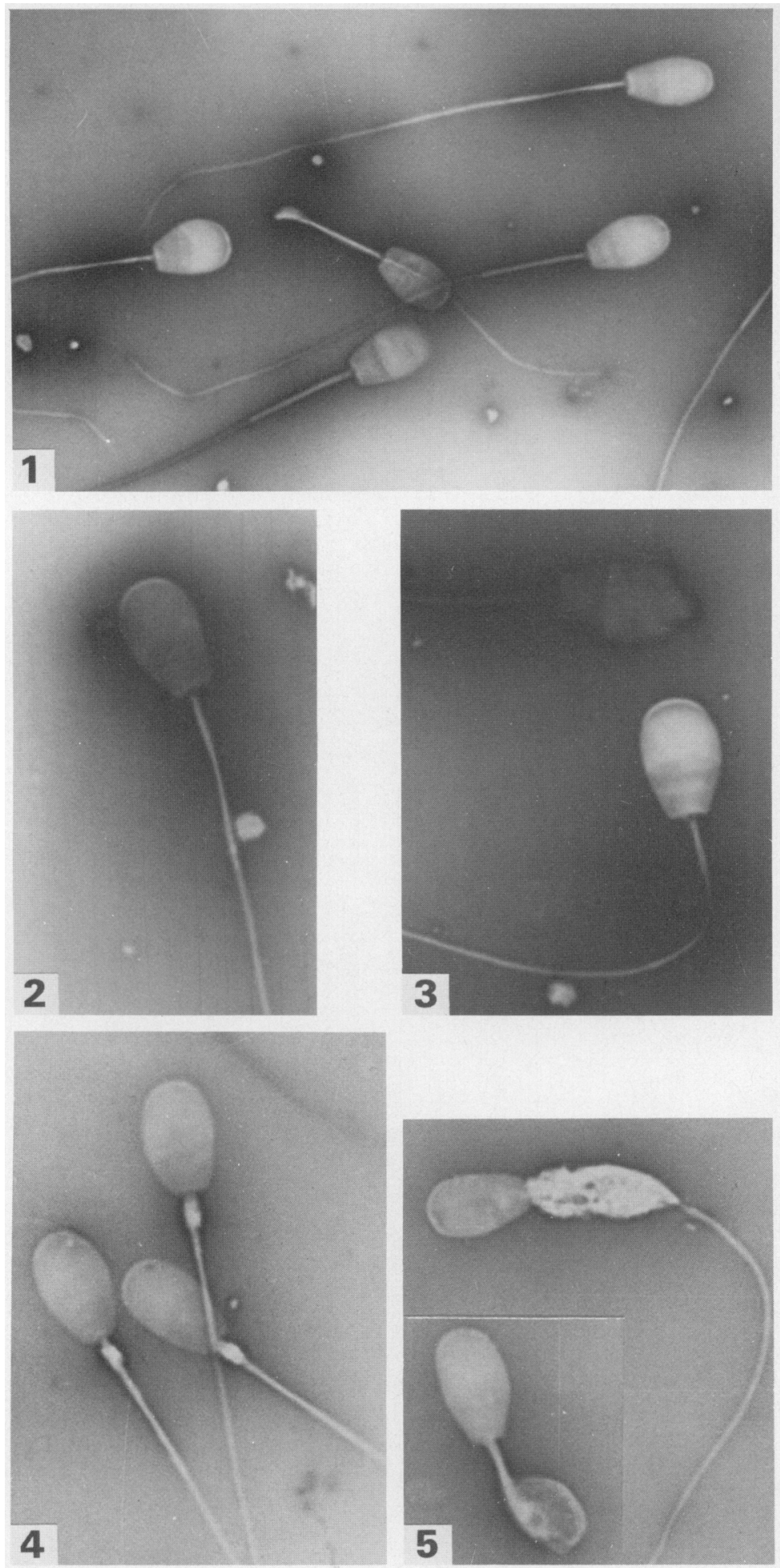

(Facing p. 416) 
Wapiti spermatozoa had the same general appearance as those of domestic ruminants. Various defects were seen of which droplet and midpiece defects were the most common (P1. 1, Figs 1-5). The droplets seen on 15 April (Pl. 1, Fig. 5) were large and irregular in outline. The number of proximal droplets was high in July and August but the proportion of normal cells rose with each collection. By the beginning of September bulls $>3$ years old had reached their peaks in terms of percentage of normal spermatozoa in ejaculates. The percentage of morphologically normal spermatozoa in ejaculates remained near peak levels until the end of March. In April it once again became difficult to obtain ejaculates containing spermatozoa and, when samples were obtained, there were large numbers of abnormal spermatozoa present.

\section{Discussion}

The endocrinological data reported here can only be regarded as a preliminary examination of the variability of androgen profiles in wapiti. The dramatic changes in circulating serum testosterone concentrations observed may reflect changes in testicular testosterone concentrations similar to those reported in red deer by Lincoln (1970) (increases of greater than 1000-fold between spring and maximum levels during the rut). Lincoln (1971) also found marked changes in testicular testosterone levels with season in yearling and 2-year-old red deer but maximum levels per gram of tissue did not occur at the same times as peak levels in adults. Rawlings, Hafs \& Swanson (1972) found that plasma and testicular testosterone values were highly correlated in domestic bulls.

The dramatic increases and abrupt decline in androgen concentration seen in this study were directly correlated with the attainment of maximum scrotal circumference and maximum percentage of morphologically normal spermatozoa. Amongst other species in which these marked seasonal changes in testicular size occur, similar observations have been made. Peak testicular or serum testosterone levels around the time of the rut have been recorded in black-tailed deer (Odocoileus hemionus columbianus) (West \& Nordan, 1976), white-tailed deer (O. virginianus) (Bubenick, Morris, Schams \& Claus, 1982), reindeer and caribou (Rangifer tarandus) (Whitehead \& McEwan, 1973; Leader-Williams, 1979) and red deer (Lincoln, 1970, 1971).

In this study the 7-year-old wapiti had the greatest scrotal circumference and most often produced semen of good quality in terms of morphology. The 4-, 5- and 10-year-old bulls did produce good quality semen at some time during the study, but less often than the 7-year-old. These data fit the general scheme of red deer maturation and decline proposed by Lincoln (1981) and the hypothesis that 7-year-old bulls of either subspecies are prime (Lincoln, 1970; Flook, 1970).

Scrotal circumference is used in the evaluation of potential breeding soundness in domestic bulls (Chenoweth \& Ball, 1980). The correlation between scrotal circumference and testicular weight is high (Willett \& Ohms, 1957; Hahn, Foote \& Seidel, 1969). Repeatability of scrotal circumference measurements is also high, both between technicians and over time (Hahn et al., 1969). The correlation between scrotal circumference and sperm output in domestic bulls declines with age, but is high in young bulls subjected to exhaustion trials (Willett \& Ohms, 1957). Mickelsen, Paisley \& Dahmen (1981) noted a correlation between maximum scrotal circumference and maximum percentage of normal spermatozoa in sheep (Ovis spp.).

In similar studies in black-tailed deer West \& Nordan (1976) used an orchidometer to study changes in testicular size. They found a 3-5-fold increase in testis volume from May to the peak of the rut in November, followed by a similar decline from January to March. Concurrently, they recorded a rising sperm output from May to November in electroejaculated deer.

Some of the changes during the year in this group of wapiti appeared to occur with more than one peak, but the sample was too small to show significant changes at these times (Text-fig. 3).

In domestic sheep two annual peaks in the percentage of normal spermatozoa have been reported (Cupps, McGowan, Rahlmann, Reddon \& Weir, 1980; Mickelsen et al., 1981). Furthermore, endocrine and histological studies in red deer, white-tailed deer, black-tailed deer and roe deer (Capreolus capreolus) indicate that the seasonal rhythm does not have just one peak. Bubenik, Bubenik \& Zamecnik (1979) showed that two peaks of oestradiol-17 $\beta$ occur in mature 
white-tailed deer, one in October/November, just before the rut, and the other in April/May at the beginning of antler production. Bubenik et al. (1982) have demonstrated two peaks in gonadotrophin activity in white-tailed deer. First an LH peak in July and an FSH peak in September and subsequently synchronous increases in March, although there was no rise in serum testosterone related to the March rise in gonadotrophin levels. In roe deer an annual biphasic elevation in testosterone concentrations during 2 consecutive years has been reported (Giménez, Barth, Hoffmann \& Karg, 1975).

Frankenberger (1953) observed changes in the proportion and absolute numbers of testicular interstitial cells in red deer shot throughout the year. Peaks occurred before the rut in late August followed by a decline and another peak in January. West \& Nordan (1976) noted that spermatogenic activity in black-tailed deer was at a peak in November and declined sharply through January to March. However, in May spermatogenic activity was observed in nearly all tubules, but had declined again by July.

Our present results for wapiti suggest that some renewed testicular activity may have been occurring in late January and early February but are inconclusive, probably because of the small sample size. Further investigation is required.

\section{References}

Ball, L. (1980) Semen collection by electroejaculation and massage of the pelvic organs. In Current Therapy in Theriogenology, pp. 345-347. Ed. D. A. Morrow. W. B. Saunders Co., Philadelphia.

Bubenik, G.A., Bubenik, A.B. \& Zamecnick, J. (1979) The development of circannual rhythm of estradiol in plasma of white-tailed deer (Odocoileus virginianus). Comp. Biochem. Physiol. 62A, 869-872.

Bubenik, G.A., Morris, J.M., Schams, D. \& Claus, A. (1982) Photoperiodicity and circannual levels of LH, FSH and testosterone in normal and castrated male white-tailed deer. Can. J. Physiol. Pharmacol. 60, 788-793.

Chenoweth, P.J. \& Ball, L. (1980) Breeding soundness evaluation in bulls. In Current Therapy in Theriogenology, pp. 330-339. Ed. D. A. Morrow. W. B. Saunders Co., Philadelphia.

Cook, S.J., Rawlings, N.C. \& Kennedy, R.I. (1982) Quantitation of six androgens by combined high performance liquid chromatography and radioimmunoassay. Steroids 40, 369-380.

Cupps, P.T., McGowan, B., Rahlmann, D.E., Reddon, A.R. \& Weir, W.C. (1980) Seasonal changes in the semen of rams. J. Anim. Sci. 19, 208-213.

Flook, D.R. (1970) Causes and implications of an observed sex differential in the survival of wapiti. Can. Wildl. Serv. Report Series No. 11.

Follis, T.B. (1972) Reproduction and hematology of the cache elk herd. Ph.D. thesis, Utah State.

Frankenberger, Z. (1953) Interstitialni bunky jelina (Cervus elaphus L.). Ceskoslovenska Morfologie 1, 36$4 !$.

Giménez, T., Barth, D., Hoffmann, B. \& Karg, H. (1975) Blood levels of testosterone in the roe deer (Capreolus capreolus) in relationship to the season. Acta endocr., Copenh. Suppl. 193, 59.

Guinness, F., Lincoln, G.A. \& Short, R.V. (1971) The reproductive cycle of the female red deer, Cervus elaphus L. J. Reprod. Fert. 27, 427-438.

Hahn, J., Foote, R.H. \& Seidel, G.E., Jr (1969) Testicular growth and related sperm output in dairy bulls. $J$. Anim. Sci. 29, 41-47.
Krzywinski, A. \& Jaczewski, Z. (1978) Observations on the artificial breeding of red deer. Symp. Zool. Soc. Lond. 43, 271-287.

Leader-Williams, N. (1979) Age-related changes in the testicular and antler cycles of reindeer, Rangifer tarandus. J. Reprod. Fert. 57, 117-126.

Lincoln, G.A. (1970) The reproductive physiology and behaviour of the red deer stag. Ph.D. thesis, University of Cambridge.

Lincoln, G.A. (1971) The seasonal reproductive changes in the red deer stag (Cervus elaphus). J. Zool., Lond. $163,105-123$.

Lincoln, G.A. (1981) Seasonal aspects of testicular function. In The Testis, pp. 255-302. Eds H. Burger \& D. de Kretser. Raven Press, New York.

Mickelsen, W.D., Paisley, L.G. \& Dahmen, J.J. (1981) The effect of season on the scrotal circumference and sperm motility and morphology in rams. Theriogeno$\log y$ 16, 45-51.

Rawlings, N.C., Hafs, H.D. \& Swanson, L.V. (1972) Testicular and blood plasma androgens in Holstein bulls from birth through puberty. J. Anim. Sci. 34, $435-440$.

Struhsaker, T.T. (1967) Behaviour of elk (Cervus canadensis) during the rut. $Z$. Tierpsychol. 24, 80-114.

West, N.O. \& Nordan, H.C. (1976) Hormonal regulation of reproduction and the antler cycle in the male Columbian black-tailed deer (Odocoileus hemionus columbianus). Part I. Seasonal changes in the histology of the reproductive organs, serum testosterone, sperm production and the antler cycle. Can. J. Zool. 54, 1617-1636.

Whitehead, P.E. \& McEwan, E.H. (1973) Seasonal variation in the plasma testosterone concentration of reindeer and caribou. Can. J. Zool. 51, 651-658.

Willett, E.L. \& Ohms, J.I. (1957) Measurement of testicular size and its relation to production of spermatozoa by bulls. J. Dairy Sci. 40, 1559-1569. 